\title{
Team Performance in Flood Emergency Response: A Conceptual Model and Scale Development
}

\author{
${ }^{1}$ Faculty of Science and Humanities Studies, \\ University Shaqra, Durmah, Saudi Arabia; \\ ${ }^{2}$ School of Computing, Faculty of Engineering, \\ University Technology Malaysia, 81310 Johor Bahru, Johor, Malaysia; \\ ${ }^{3}$ School of Industrial Engineering, Telkom University, \\ 40257 Bandung, West Java, Indonesia.
}

Naglaa Abdel Lateef Saeed ${ }^{1}$, Nor Hidayati Zakaria ${ }^{2}$, Edi Sutoyo ${ }^{3}$

Received 28 June 2018; accepted 5 August 2018, available online 24 August 2018

\begin{abstract}
Based on findings from the existing literature regarding the used knowledge integration, social media, and emergency management, this paper presents a conceptual model for Emergency Management Team Performance (EMTP) and provides a rigorous approach in scale development and validation. The model is meant to improve organizations volunteer and staff per on flood field. Thus, this study conceptualizes the construct of EM team performance and generates an initial 39 item on EM task scale. Based on the sample data, we provided an empirical validation of the Emergency Management Team Performance (EMTP) constructs and its underlining dimensionality and developments a generic Emergency Management Team (EMT) scale with desirable psychometric properties, which includes face validity, content validity and pilot testing. In the validation process, a 30-item EM task scale with 6 constructs (task characteristic, task-technology, task-technology fit, social media usage, knowledge integration and EM team performance) were used. This study is a pioneering effort to develop and validate EMTP scale and will contribute to the development of knowledge integration while adding to the repository of rigid research instruments for researcher's utilization.

Keywords: knowledge integration, social media, emergency management team performance and scale development
\end{abstract}

\section{Introduction}

Flood is considered as one of the most common natural disasters [1]. Flooding is one of the costliest disasters and the impact can lead to human injury, death, and destruction of infrastructure. Furthermore, due to its annual and repeated re-occurrences, it has recorded high volume of life losses and undeniable effects on people's property and infrastructure. Thus, prevention of such events is preferable to compensation of damages [2]. A flood can be defined as an overflow that comes from a river or other body of water and causes or threatens damage [3]. Ahmad, Othman [4] defined flood, as "the phenomenon of water rising, swelling and overflowing land which is not usually covered”.

Flood damage constitutes about 30 percent of the economic losses caused by natural hazards globally, especially in under-developed countries. In Nigeria precisely, recent years have experienced flooding as a major hazard. It was estimated that Nigeria suffered combined losses of more than $\$ 16.9 \mathrm{~b}$ due to flood events in 2012 alone [5]. Statistically, flood takes $83.3 \%$ of all disaster that happened in Nigeria from 1990 -2014 and $84.4 \%$ of death recorded during the period is from flood [6]. Similarly, there is an estimated cost of MYR1 billion as a lost which is reported annually in Malaysia as a result of the effect of disaster on $21 \%$ of the country's population that are residing in about $9 \%$ of the total 328,938 sq $\mathrm{km}$ of the country [7]. In Sudan, flood as dangerous disaster is common term due to its re-recurrences annually because of change in weather, social, and poor economic conditions, heavy and clustered population, and unawareness in public and limited resources. Sudan has a vast flat terrain in most of its parts, which increases the risk of flooding due to local rains and the flow of rainwater from the neighboring countries [8]. In addition, more than $70 \%$ of Sudan falls within the Nile basin and this river highly significant to the region since about $85 \%$ of the population depends on it [9]. The White Nile flows 
from Lake Victoria which is one of the main tributaries of the Nile River, in Uganda to South Sudan, therefore the cause of flood in Sudan is not just heavy rain in the country, rather, weather conditions of bordering countries such as intensive rains in African countries (Uganda, Eritrea and Ethiopia) [10].

Nevertheless, information and knowledge have been considered very crucial in aiding interactions and coordination between related agencies in disaster response operations [3]. Emergency management tasks are characteristically complex and dynamic in terms of required accurate, speed information and sharing with organizations and teams to locate and deliver required supplies and evacuate affected people [11].

Besides collecting reliable information and knowledge, it should be shared quickly and efficiently between the responsible parties' inappropriate time and place $[12,13]$. Hence, there is a need for effective communication to provide knowledge and skills to the emergency managers in order to carry out prompt evacuation plans and share this information with volunteers and staff team to help people in the affected area. However, obtaining accurate and reliable data and sending the required information to the volunteers and staff teams existing in the affected area in which they need to be present is difficult, most especially amongst the NGOs [8]. Identifying the best way to approach emergency response tasks is vital and improving the performance in emergency management depends to a greater extent the ability of managers, volunteers and staff teams to coordinate and share their knowledge and information. Previous studies confirm that the biggest problem faced by organizations during a disaster in developing countries is the communication [14-16].

For instance NGOs in Sudan as an example of developing country is suffering from miscommunication and coordination amongst the teams at different level of organizations in dispersed places, especially during the first phase of the emergency especially with roads blocked, and damaged bridges due to the effect of flooding and radio equipment malfunctioning which is so rampant in developing countries [9]. In addition, Knowledge is considered to be an organizational asset and has significant influences on organizational performance [10]. Flood knowledge was integrated in teams having a diversity of authorities, agencies, backgrounds, and disciplines. In other word, in order to have better knowledge integration, those authorities, and agencies need to realize their different roles and responsibilities, and therefore it becomes important for different actors in the area to integrate knowledge to successfully manage the impact of flood disaster [11]. Knowledge Integration (KI) involves the process of identifying knowledge in similar fields and integrating that knowledge to create new knowledge that is able to deliver the expected solutions to problems or minimize the complexity of tasks [4]. The process of KI will deliver the creation of new knowledge and improvise existing knowledge for the purpose of decision-making, so that knowledge becomes an instrument for better job enhancement [12]. However, there are limitations in term of tools and theory that should be used by the teams in diverse organizations based on the emergency management success through knowledge integration as well as handling task [13]. Hence, few studies thus examined basic impact for integrating knowledge on both team efficiency and effectiveness [14]. Though, the investigation of knowledge integration and its relation to teamwork and team performance provide awareness to potentially support team and organizational learning efforts as well as reveals key issues in team training, yet, there are limitations in term of research conducted in this field [15]. As a step towards bridging this gap, the present study has developed a conceptual model integrating the KBT and TTF theories, as well as proposing a rigorous approach to scale development and validation.

\section{Literature Review}

\subsection{Emergency Management}

In Emergency management of natural disasters, there is need to have a swift interaction and communication of accurate information, in order to save lives and property [16]. As a result, the emergency management directives among decision makers may be conflicting $[12,17]$. In a simpler form, emergency and disaster management is the process of handling and avoiding risk. Risk again leads to diverse range of problems and may involve different players[18]. Emergency is defined as an imminent actual event that threatens people, property, or the environment. Emergencies are the events that threaten lives and property [19]. Emergencies require coordinated and rapid response [20, 21]. During disasters, emergency services is confronted with situations for which decisions have to be made as quickly as possible [22]. The emergency plan is implemented by the emergency response phase and begins coordinating responders and other resources. Moreover, this phase formed the command and control phase that needs the response of the emergency response team to monitor situations and to coordinate response accordingly.

\subsection{Lack of Communication and Coordination}

Information system research on emergency response management regarded information and communication technology as an important tool that can be used in emergency management [23]. Similarly in IS research, disaster management have received some attention especially for activities coordination and effective information processing amongst all the stakeholders[24]. Collaboration is the best and right approach while working in these situations. Timely, efficient, reliable information exchange is critical hence require flexible and accessible communication channels for such collaborations [25]. The more elaborated definition of coordination can be seen as "a temporally recounting and a process that is contextualized relating to tasks regulation 
and interaction to realize a collective performance” [26]. The coordination includes "the activities responsible to ensure the effectiveness of the collaborative work [27]. Coordination tasks which includes information flow management and shared resources management are necessary to ensure consistency within a project [28]. According to Kotlarsky, Scarbrough [29] coordination of effort within and among different expert groups and support for such coordination is seen as one of the most influential impacts that information systems can make to enhance organizational performance. In similar way, Krumay and Brandtweiner [24] described Coordinated and fast response are key to successful disaster management. In Chandrasekhar [30], Al-Dahash and Kulatunga [31] studies, it was mentioned that in order to save lives and property, disaster response efforts need that they need to be present is difficult, most especially amongst the NGOs [12].

For instance, NGOs in Sudan as an example of developing country is suffering from miscommunication and coordination amongst the teams at different level of organizations in dispersed places, especially during the first phase of the emergency especially with roads blocked, and damaged bridges due to the effect of flooding and radio equipment malfunctioning which is so rampant in developing countries [17]. In addition, Knowledge is considered to be an organizational asset and has significant influences on organizational performance [18]. Flood knowledge was integrated into teams having a diversity of authorities, agencies, backgrounds, and disciplines. In another word, in order to have better knowledge integration, those authorities, and agencies need to realize their different roles and responsibilities, and therefore it becomes important for different actors in the area to integrate knowledge to successfully manage the impact of the flood disaster [19]. Knowledge Integration (KI) involves the process of identifying knowledge in similar fields and integrating that knowledge to create new knowledge that is able to deliver the expected solutions to problems or minimize the complexity of tasks [4]. The process of KI will deliver the creation of new knowledge and improvise existing knowledge for the purpose of decision making, so that knowledge becomes an instrument for better job enhancement [20].

Timely and coordinated emergency response services. Similarly, Cozzolino [32], Glenn Richey Jr, Kovács [33], Kabra, Ramesh [34] also emphasized on the fact that effective coordination between the relief actors, would have great impact towards mitigating the effect of the calamity.

Furthermore, improper coordination in history has led to decrease in productivity and slowing the objectives [25, 35]. Many literature consensus, of the importance of coordinated relief activities to responding to the needs of people affected by disasters [34, 36, 37]. In comparable way, the coordination on agency and groups in emergency response management is considered one greater challenge for these agencies [25] . Although, lack of direct coordination among first responders is perceived as one of the major operational impediments experienced during system responses to large-scale emergencies [38]. Therefore, during emergency response operations and specialized operational expertise, need to coordinate their actions across organizational boundaries [39]. Effective coordination itself implies the need to ensure sound communication of team members to comprehend each other's roles and responsibilities prior to emergency occurrence [40].

\subsection{Knowledge Integration: A theoretical View Point}

Knowledge regarded as a critical resource for the firm [41, 42], and it can be considered as the most strategically important of the firm's resources [43]. Knowledge is a 'justified personal belief' [44]. According to Szulanski [45], incorporation of diverse kinds of knowledge could be achieved by interaction, participation, and engagement. Knowledge could be tacit or explicit. Tacit knowledge is described as the knowledge which cannot be expressed in words, while explicit knowledge is that which can be expressed in words and numbers [16, 44]. Explicit knowledge can be transmitted in formal, as a result, it can be codified whereby the tacit knowledge is personal and context specific, and is thus hard to formalize and communicate in formal [46]. In recent perspectives on knowledge integration, knowledge is described as inclusive of information, technology, know-how and skills $[43,47]$. The KI process requests the knowledge to be practical in nature and applicable, when needed by the organization. It involves the process of identifying knowledge of similar fields; integrate that knowledge to create a new knowledge that able to deliver the expectation as solutions to problems or complexity of tasks. Furthermore, knowledge integration produces knowledge with certain documents that later archived in the repository [48]. In the context of emergency management, there are more awareness among the team members on the performance implications of their actions as well as increase understanding of these causal links to introduce the necessary services during response flood disaster [49, 50]. Hence, an individual's knowledge is expressed via cooperative discussion and routine processes for evaluation. In addition, employing formal mechanisms enables team members to organize their performance implications and codify their routines by means of memos or other forms of written tools [49-51]. Often, most of these tools can be facilitated as guidelines or directions in controlling development of new routines. Also, team members can further recognize and understand causal link among decisions and expected performance outcomes using codified knowledge [49]. Knowledge integration is quite effortful and requires a significant investment of team's cognitive and social energies in activities such as combining multiple expertise and skills to develop a shared understanding of non-routine problems or blending new knowledge with what the team already knows [14].

Furthermore, knowledge integration not only requires team members to jointly solve team-level problems, but 
also requires them to build on each other's ideas, skills, and expertise, and to gain new learning for accurate decision making [52]. According to Mehta and Mehta [14] prior research has affirmed that knowledge integration deeply influences team outcomes, such as creativity, despite this little of research focus on the influence of knowledge integration on team effectiveness outcomes. The knowledge existing among an organization is basically distributed in highest capacity and not willingly available where it is needed. Due to the nature of work for teams dispersed on diverse locations. The problem of dispersed knowledge suggests the value of Knowledge Integration (KI), which denotes the combination and systematization of individuals' knowledge to make it available to others as valuable, context-sensitive knowledge [53].

Thus, it was mentioned that social media allows participants to freely produce, arrange, find and share content. Example of such social media is Facebook Twitter or WhatsApp where it's possible for people to work together for create, compile, and update knowledge [54].

\subsection{Social Media (SM)}

Social media is one of the most important technological development in the past two decades and it enables everyone to collaborate and share information, with anyone in the world. This platform provides a robust capability to enhance the information exchange. The effect of this robustness can be seen in the number of subscribers and the avalanche of information processed on the platform [55]. Previous studies define the social media (SM) as "the set of platforms that enable people to connect, communicate, and collaborate $[41,56]$ and share experiences [57]. SM platforms make possible an enhanced collaborative environment (Shang et al., 2017).
It also makes possible a faster information transfer, facilitates interaction amongst team members [58]. And it was considered as providing timely, widespread data collection and dissemination as well as providing a reliable communication channel with teams [59]. Thus, organizations can utilize social media to facilitate the task of the teams and collaborate with them instead of face-toface meetings [60].

\section{A Conceptual Model of Emergency Management Performance}

The study attempted to examine the key factors affecting emergency management task performance, by combining Task-Technology Fit (TTF) theory and Knowledge-Based Theory (KBT) of the firm. KBT is a theory of knowledge integration [65]. While TTF theory argues that, the use of a technology may result in different outcomes, depending upon its configuration and the task [66].

The conceptual model shows the interrelationships between variables that are prominent for the study. The conceptual model that was developed should allow certain relationships to consider whether the theory formulated is valid or not based on testing and hypothesizing [67].

TTF theory is significant in introducing Task, Technology Characteristics and the concept of fit between them. TTF model is commonly used to evaluate how performance is leads by information technology by assessing the match among the task and technology characteristics [68-70]. Fig. 1 illustrates a combined model for the KBT and TTF theory.

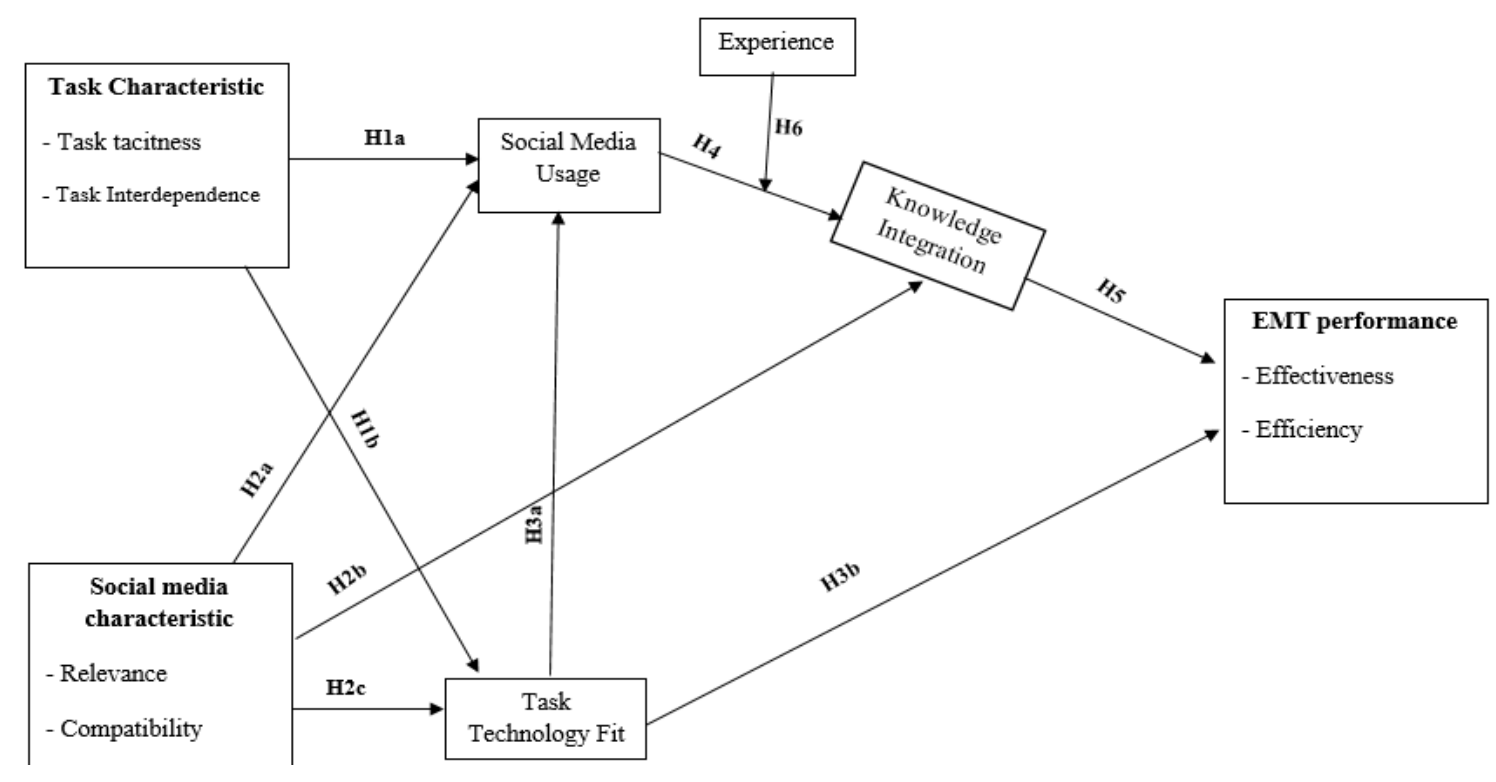

Fig. 1: Conceptual Model according to KBT and TTF Theory 
It also considers whether combinations of Task and Technology Characteristics cause a certain "fit" that leads to increased performance when a direct relationship cannot be established.

The relationships of TTF that influence the performance are also well documented in knowledge management research [61-64]. Therefore, the following hypotheses are examined:

H1b: Task characteristic has a positive effect on task technology fit.

H3b: Task - technology fit has the positive influence on emergency management task performance.

H2c: Social media characteristics are positively related to task - technology fit. Social media has proven to be helpful in disaster management operations. In addition, it can be used to disseminate critical information, to guide volunteers and to help reconnect families [65].

Therefore, SM characteristics are designated as the technological dimension help to complete the task, use for search, and contribute knowledge. Task interdependence is the extent to which, individuals perceive that they interact with and depend upon others to accomplish their work. This means that when people realize their tasks and performances are heavily dependent on one another is likely to share information, knowledge, or materials [66]. Therefore, the following hypotheses are suggested:

H2a: Social media characteristics positively influence the social media usage.

H1a: Task characteristic positively influences the social media usage.

In this study, utilization refers to the use or continuous use of technology. It is the behavior of employing technology in completing tasks [75]. In the TTF model, technology utilization depends on the fit between technology and the tasks it supported [76].

H3a: Task-technology fit has a positive effect on Social media usage.

As mentioned earlier, social media has proven to be helpful in disaster management operations and it is known to help in facilitating information transfer [77] it is useful in storing, capturing, and sharing knowledge to another recipient to integrate with a mind as skills knowledge to introduce services and decision making on the appropriate time.

H4: Social media usage positively and significantly affects knowledge integration.

H2b: Social media characteristics positively affect knowledge integration.

Many authors argued the important role of knowledge integration on Multi area [56, 78]. Körner, Lippenberger [79], which argued that team members typically assimilate knowledge by communicating verbally, coordinating their expertise, skills and by sharing information about who knows what in teams. Mehta and Mehta [55] stated the accurate and suitable time to make critical decisions effect to enhance team performance on management emergency response. The availability of accurate and timely knowledge enables team's members to respond rapidly to problems and facilitate tasks [80]. Knowledge integration involves having one's knowledge built upon, or combined with others' ideas, to generate new insights. Likewise, it is probable that the act of combining each other's knowledge to achieving team goals would (i) give team members the sense that they could work well together to solve problems, and (ii) demonstrate the competence of team members[14].

\section{Moderators:}

In addition to these 5 hypotheses, the moderating effects of variables (experience) on the strength of social media usage with knowledge integration relationships were included to be investigated.

The actual experience of utilizing the technology may lead users to conclude that the technology has a positive or negative impact on performance. And thereby establishing future usability and utilization of such technology[66].

H6: Experience positively moderates the relationship between SM usage and knowledge integration where the relationship is stronger among the ones with higher experience.

\section{Scale Development and Validation Process}

Based on previous studies in knowledge integration, utilization technology and performance of team such as Lin and Huang [64], Gudi [67], Tiwana and Mclean [68], Subramaniam and Venkatraman [69], Pearce and Gregersen [70], King'ori [71]comprehensive item pool (38)was generated drawn from existing literature and (1) item developed by researcher for this study, in developing and validating a multi-item measure of EM task performance, this study adopts the scale development guidelines recommended by Öberseder, Schlegelmilch [72], Netemeyer, Bearden [73], Churchill Jr [74]. Generation of the initial item pool and assessment of the content validity of the item were followed by above studies, which aimed to refine the measurement scale. Additionally, the items were scaled in Likert format anchoring from 1 ("strongly disagree") to 5 ("strongly agree”) for the follow-up analyses as illustrated in Fig. 2.

\footnotetext{
* Naglaa Abdel Lateef Saeed: golya_abd@hotmail.com 2018 UTHM Publisher. All right reserved. penerbit.uthm.edu.my/ojs/index.php/ijie
} 


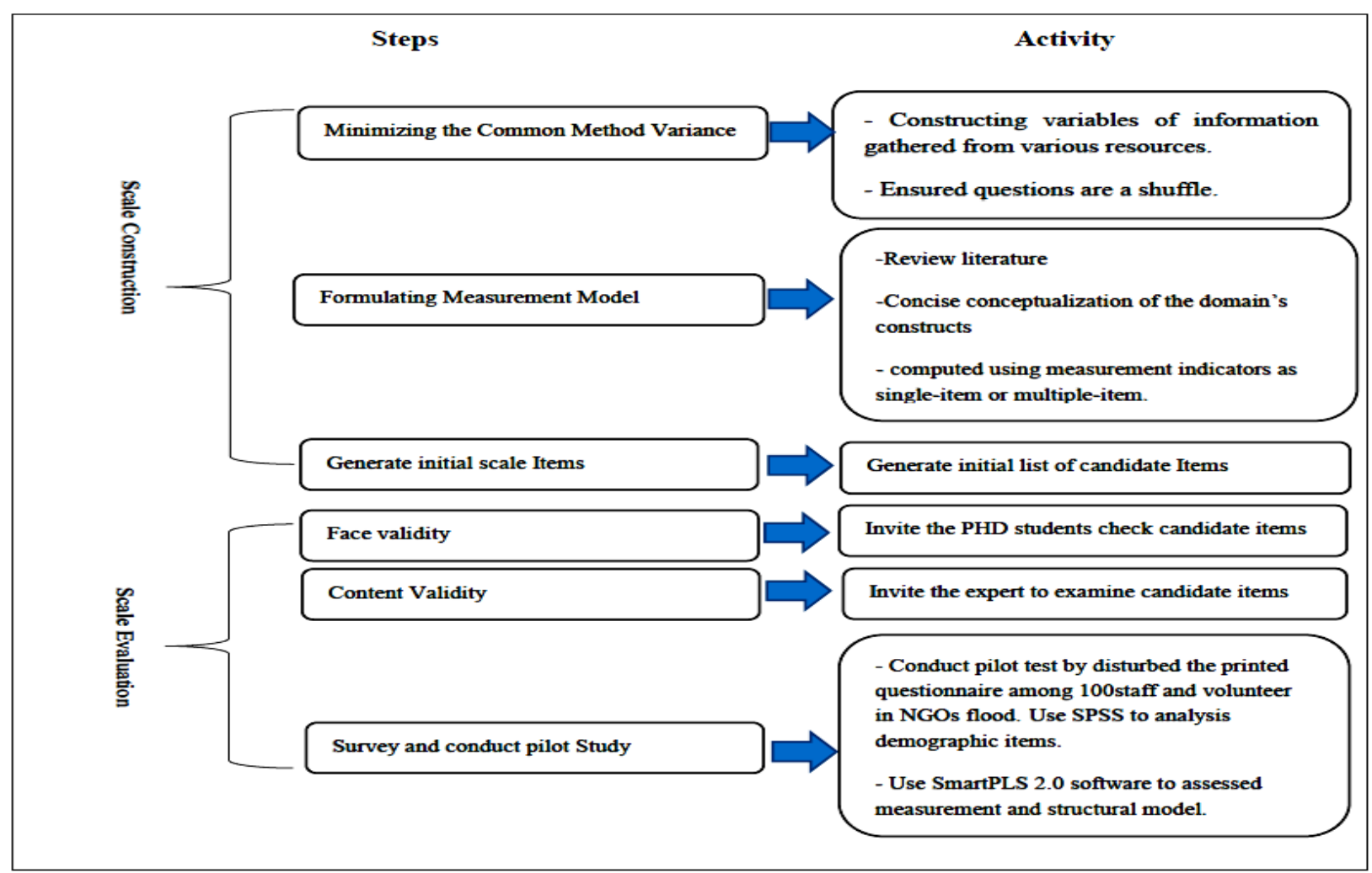

Fig. 2: Overview of the Scale Development and Validation Process

\subsection{Scale Construction}

During the data collection, the researcher was careful, so that the study does not deviate from actual context, which is knowledge integration by using the Common Method Variance technique, and then formulating measurement model is an essential step in the scale development, which concise conceptualization of the domain's constructs. In this study, all the constructs applied in this study already exist in the literature in knowledge integration and utilization technology and driven from the theoretical foundation. Addition to all scale items modified from previous studies except one from the author, that resulted in an initial pool of 39 scale items projected to capture the six construct of team performance in flood emergency management. Table 1 provides the Management model. 
Table 1: Measurement Model

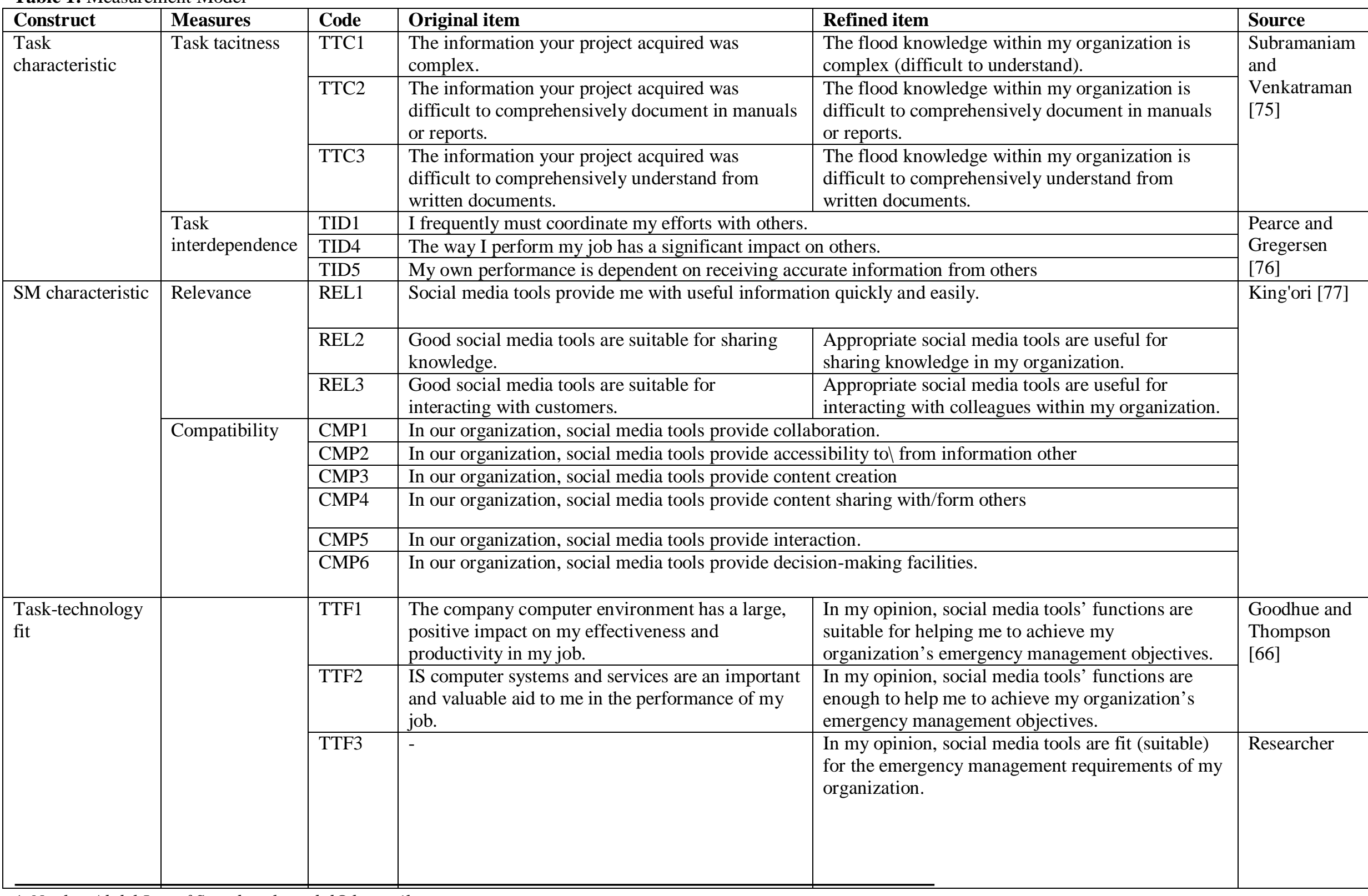

* Naglaa Abdel Lateef Saeed: golya_abd@hotmail.com

.

penerbit.uthm.edu.my/ojs/index.php/ijie 
Naglaa et al., Int. J. Of Integrated Engineering: Special Issue 2018: Data Information Engineering: Vol. 10 No. 6 (2018) p. 37-48

\begin{tabular}{|c|c|c|c|c|c|}
\hline Construct & Measures & Code & Original item & Refined item & Source \\
\hline \multirow[t]{3}{*}{ SM usage } & & SMU1 & $\begin{array}{l}\text { I frequently use KMSs to search knowledge in my } \\
\text { work. }\end{array}$ & $\begin{array}{l}\text { Social media tools are frequently used to search } \\
\text { emergency management related knowledge in this } \\
\text { organization. }\end{array}$ & \multirow[t]{3}{*}{$\begin{array}{l}\text { Lin and } \\
\text { Huang [78] }\end{array}$} \\
\hline & & SMU2 & $\begin{array}{l}\text { I frequently use KMSs to contribute knowledge in } \\
\text { my work }\end{array}$ & $\begin{array}{l}\text { Social media tools are frequently used to contribute } \\
\text { knowledge in this organization. }\end{array}$ & \\
\hline & & SMU3 & $\begin{array}{l}\text { I regularly use KMSs to search knowledge in my } \\
\text { work }\end{array}$ & $\begin{array}{l}\text { Social media tools are regularly used to search } \\
\text { knowledge in this organization. }\end{array}$ & \\
\hline \multirow[t]{4}{*}{$\begin{array}{l}\text { Knowledge } \\
\text { integration }\end{array}$} & & KI1 & $\begin{array}{l}\text { Members of this team synthesize and integrate } \\
\text { their individual expertise at the project level. }\end{array}$ & $\begin{array}{l}\text { Staff and volunteer of our organization synthesize } \\
\text { and integrate their individual expertise at the } \\
\text { emergency management level. }\end{array}$ & \multirow{4}{*}{$\begin{array}{l}\text { Tiwana [79] } \\
\text { and Tiwana } \\
\text { and Mclean } \\
\text { [80] }\end{array}$} \\
\hline & & KI2 & We applied our expertise in innovative ways & $\begin{array}{l}\text { We applied our expertise in innovative ways to } \\
\text { handle emergency related issues. }\end{array}$ & \\
\hline & & KI3 & $\begin{array}{l}\text { We carefully made decisions to maximize overall } \\
\text { project outcomes }\end{array}$ & $\begin{array}{l}\text { We carefully made decisions to maximize overall } \\
\text { emergency management outcomes. }\end{array}$ & \\
\hline & & KI4 & $\begin{array}{l}\text { We leveraged the customer's knowledge in many } \\
\text { functional areas }\end{array}$ & $\begin{array}{l}\text { We leveraged the staff and volunteer's knowledge } \\
\text { in many functional areas related to emergency } \\
\text { management. }\end{array}$ & \\
\hline \multirow[t]{5}{*}{ EM performance } & \multirow{2}{*}{$\begin{array}{l}\text { Task } \\
\text { effectiveness }\end{array}$} & EFT3 & \multicolumn{2}{|c|}{ The task in our organization was completed within the planned number of person-hours } & \multirow[t]{5}{*}{ Gudi [81] } \\
\hline & & EFT4 & \multicolumn{2}{|c|}{ In this organization, the task in our organization was completed within the planned time schedule } & \\
\hline & \multirow[t]{3}{*}{ Task efficiency } & EFC1 & \multicolumn{2}{|c|}{ In this organization, the task was completed within the allocated budget } & \\
\hline & & EFC2 & \multirow{2}{*}{\multicolumn{2}{|c|}{ In this organization the task was completed within the planned number of person-hours }} & \\
\hline & & EFC3 & & In this organization, the task was completed with efficient use of all available resources & \\
\hline
\end{tabular}




\subsection{Scale Validation}

After developing an initial measurement instrument, a series of quantitative pre-tests have been conducted with the focus on the items' refinement and exclusion of bad ones from the initial survey, such as face and content validity that conduct by $\mathrm{PhD}$ students and as well as invite experts from academic and field and pilot study which printed questionnaire was distributed to 100 of staff and volunteer work in flood NGOs for review and refinement. To test the reliability of the designed survey questionnaire, PLS-SEM algorithms were applied using SmartPLS 2.0 software. Cronbach's alpha and composite reliability $\left(\mathrm{P}_{\mathrm{C}}\right)$ were computed for assessing the internal consistency reliability of constructs. Referring to Table 1, all constructs met the acceptable values for criteria of Cronbach's alpha and composite reliability $\mathrm{P}_{\mathrm{C}}$ ) which should be more than $0.7[82]$.

Table 2: Internal consistency reliability

\begin{tabular}{|l|c|c|}
\hline Construct & $\begin{array}{c}\text { Cronbach's } \\
\text { Alpha }\end{array}$ & $\begin{array}{c}\text { Composite } \\
\text { Reliability, } \\
\left(\rho_{c}\right)\end{array}$ \\
\hline $\begin{array}{l}\text { Emergency task } \\
\text { performance }\end{array}$ & 0.884 & 0.916 \\
\hline $\begin{array}{l}\text { Knowledge } \\
\text { integration }\end{array}$ & 0.871 & 0.911 \\
\hline $\begin{array}{l}\text { Social media } \\
\text { characteristics }\end{array}$ & 0.924 & 0.936 \\
\hline Social media usage & 0.776 & 0.868 \\
\hline $\begin{array}{l}\text { Task } \\
\text { Characteristics }\end{array}$ & 0.880 & 0.913 \\
\hline $\begin{array}{l}\text { Task-technology } \\
\text { fit }\end{array}$ & 0.811 & 0.889 \\
\hline
\end{tabular}

\section{Conclusion}

The primary aim of this study is to develop and validate a scale and model for measuring team performance in flood emergency management, for effective application for future empirical studies of applied knowledge integration to enhance team performance management by using social media platform. We have conducted a systematic literature review methodology [83] in order to identify the current scale. A pool of 39 items of team performance in flood emergency management was developed. The scale development and validation process will be continued, and we will be able to report the finalized scale, and we will develop a conceptual model by integrated two theories tasktechnology fit and knowledge-based theory of the firm, which shows how the concept is formed, and team performance emergency management. In addition to there has been lack of studies carried out to examine the fit of using a social media to share knowledge in the event of a natural disaster specifically on flood. The TTF model is focused on the impacts on task performance without addressing the factor of Knowledge integration to understand its impacts on the team.
Based on this current work, we believe it will enrich existing work in emergency management and knowledge integration through the utilization of social media. This study proffers a comprehension of knowledge integration and social media engagement on flood emergency management. Therefore, the findings of this study could also provide NGOs with a novel way to decide upon how to adopt these powerful social tools and how knowledge integration should be invested.

\section{References}

[6] Ganiyu, M.A., R. Mohammed, and A. Ismail, Effective Media Involvement in Flood Disaster Management in Nigeria: Pressing Problems and Recommendations. 2017.

[7] Othman, M., et al., COBIT principles to govern flood management. International Journal of Disaster Risk Reduction, 2014. 9: p. 212-223.

[8] Debnath, P., et al., Post-disaster Situational Analysis from WhatsApp Group Chats of Emergency Response Providers, in ISCRAM. 2016.

[9] OCHA. Rains, floods destroy hundreds of South Darfur homes. 2016 [cited 2017.

[10] Oztekin, A., et al., The influence of knowledge management on financial and non-financial performance. Journal of Information \& Knowledge Management, 2015. 14: p. 1550013.

[11] Zakaria, N.H., et al., Knowledge Integration Improves Flood Disaster Management: A Case Study of Kemaman. 2016.

[12] Rodzi, M.Z.M., N.H. Zakaria, and M.N. Ahmad, Ontology Based Knowledge Integration Framework for Managing Flood in Malaysia. Journal of Advanced Management Science Vol, 2016. 4. 
[13] Becerra-Fernandez, I., et al., Task characteristics, knowledge sharing and integration, and emergency management performance: research agenda and challenges, in Proceedings of the 5th International ISCRAM Conference-Washington, DC, USA. 2008.

[14] Mehta, A. and N. Mehta, Knowledge Integration and Team Effectiveness: A Team Goal Orientation Approach. Decision Sciences, 2017.

[15] Körner, M., et al., Knowledge integration, teamwork and performance in health care. Journal of health organization and management, 2016. 30(2): p. 227-243.

[16] Dorasamy, M., M. Raman, and M. Kaliannan, Knowledge management systems in support of disasters management: A two decade review. Technological Forecasting and Social Change, 2013. 80: p. 1834-1853.

[17] Othman, M., et al., Towards COBIT-based Framework to Govern Flood Management, in PACIS. 2013. p. 118.

[18] Haddow, G., J. Bullock, and D.P. Coppola, Introduction to emergency management. 2017: ButterworthHeinemann.

[19] Kehl, D., et al., Advancing disaster relief: Development of a self-report questionnaire for firefighters. International Perspectives in Psychology: Research, Practice, Consultation, 2014. 3(3): p. 167.

[20] Shan, S., et al., An emergency response decision support system framework for application in $e$ government. Information Technology and Management, 2012. 13(4): p. 411-427.

[21] Shan, S. and Q. Yan, Emergency Response Decision Support System. 2017: Springer.

[22] Reuter, C., et al., Social Media and Emergency Services?: Interview Study on Current and Potential Use in 7 European Countries. International Journal of Information Systems for Crisis Response and Management (IJISCRAM), 2015. 7: p. 36-58.

[23] Turoff, M., et al., The design of a dynamic emergency response management information system (DERMIS). JITTA: Journal of Information Technology Theory and Application, 2004. 5(4): p. 1.

[24] Krumay, $\mathrm{B}$. and $\mathrm{R}$. Brandtweiner, The role of information systems to support disaster management. WIT Transactions on The Built Environment, 2015. 150: p. 301-313.

[25] Ahmed, A., Use of social media in disaster management. 2011.

[26] Houtman, L., J. Kotlarsky, and B. Van den Hooff, Understanding knowledge coordination dynamics in traditional and fast-response IT organizations. 2014.

[27] Kożuch, B. and K. Sienkiewicz-Małyjurek, Interorganisational coordination for sustainable local governance: Public safety management in Poland. Sustainability, 2016. 8(2): p. 123.

[28] Lee, H.J., J.W. Kim, and J. Koh, A contingent approach on knowledge portal design for $R \& D$ teams: Relative importance of knowledge portal functionalities. Expert Systems with Applications, 2009. 36(2): p. 3662-3670.

[29] Kotlarsky, J., H. Scarbrough, and I. Oshri, Coordinating expertise across knowledge boundaries in offshoreoutsourcing projects: The role of codification.
Management Information Systems Quarterly, 2014. 38: p. 607-627.

[30] Chandrasekhar, D., Digging deeper: participation and non-participation in post-disaster community recovery. Community Development, 2012. 43(5): p. 614-629.

[31] Al-Dahash, H. and U. Kulatunga. Review of disaster response management challenges from war operations and terrorism in Iraq. in 5th International Conference on Building Resilience. 2015.

[32] Cozzolino, A., Humanitarian logistics: cross-sector cooperation in disaster relief management. 2012: Springer Science \& Business Media.

[33] Glenn Richey Jr, R., G. Kovács, and K. Spens, Identifying challenges in humanitarian logistics. International Journal of Physical Distribution \& Logistics Management, 2009. 39: p. 506-528.

[34] Kabra, G., A. Ramesh, and A. Gunasekaran, Analyzing drivers and barriers of coordination in humanitarian supply chain management under fuzzy environment. Benchmarking: An International Journal, 2015. 22.

[35] McEntire, D.A., Disciplines, disasters, and emergency management: The convergence and divergence of concepts, issues and trends from the research literature. 2007.

[36] Van Wassenhove, L.N., Humanitarian aid logistics: supply chain management in high geart. Journal of the Operational Research Society, 2006. 57: p. 475-489.

[37] Akhtar, P., Z. Khan, and C. Griffith, The linkages between leadership approaches and coordination effectiveness: a path analysis of selected New ZealandUK international agri-food supply chains. British Food Journal, 2015. 117.

[38] Salmon, P., et al., Coordination during multi-agency emergency response: issues and solutions. Disaster Prevention and Management: An International Journal, 2011. 20(2): p. 140-158.

[39] Wolbers, J. and K. Boersma, The common operational picture as collective sensemaking. Journal of Contingencies and Crisis Management, 2013. 21(4): p. 186-199.

[40] Mohammadfam, I., et al., Evaluation of Coordination of Emergency Response Team through the Social Network Analysis. Case Study: Oil and Gas Refinery. Safety and Health at Work, 2015. 6(1): p. 30-34.

[41] Hemsley, J. and R.M. Mason, Knowledge and knowledge management in the social media age. Journal of Organizational Computing and Electronic Commerce, 2013. 23: p. 138-167.

[42] King, W.R., Keynote paper: knowledge management: a systems perspective. International Journal of Business and Systems Research, 2007. 1: p. 5-28.

[43] Grant, R.M., Toward a Knowledge - Based Theory of the firm. Strategic management journal, 1996. 17: p. 109-122.

[44] Alavi, M. and D.E. Leidner, Review: Knowledge management and knowledge management systems: Conceptual foundations and research issues. MIS quarterly, 2001: p. 107-136.

[45] Szulanski, G., Exploring internal stickiness: Impediments to the transfer of best practice within the 
firm. Strategic management journal, 1996. 17(S2): p. 27-43.

[46] Nonaka, I. and V. Peltokorpi, Objectivity and subjectivity in knowledge management: a review of 20 top articles. Knowledge and Process Management, 2006. 13: p. 73-82.

[47] Haddad, M. and K. Bozdogan, Knowledge Ingtegration in Large-Scale Organizations and NetworksConceptual Overview and Operational Definition. 2009.

[48] Jane Austin, J.R.a.J.B., Towards a Comprehensive Knowledge Management Framework (CKMF): A Review on Knowledge Management Processes and Critical Success Factors 24th Australasian Conference on Information Systems 2013.

[49] Tsai, K.-H., Y.-C. Liao, and T.T. Hsu, Does the use of knowledge integration mechanisms enhance product innovativeness? Industrial Marketing Management, 2015.

[50] Zollo, M. and S.G. Winter, Deliberate learning and the evolution of dynamic capabilities. Organization science, 2002. 13: p. 339-351.

[51] DeNisi, A., A cognitive approach to performance appraisal. 2003.

[52] Mehta, N., D. Hall, and T. Byrd, Information technology and knowledge in software development teams: The role of project uncertainty. Information \& Management, 2014. 51: p. 417-429.

[53] Loebbecke, C. and M.D. Myers, Deploying internal knowledge portals: Three major challenges. Information \& Management, 2017. 54(4): p. 491-505.

[54] Cao, X., et al., The role of social media in supporting knowledge integration: A social capital analysis. Information Systems Frontiers, 2015. 17: p. 351-362.

[55] Shang, S.S., Y.-L. Wu, and E.Y. Li, Field effects of social media platforms on information-sharing continuance: Do reach and richness matter? Information \& Management, 2017. 54(2): p. 241-255.

[56] Jue, A.L., J.A. Marr, and M.E. Kassotakis, Social media at work: How networking tools propel organizational performance. 2009.

[57] Katzy, B.R., K. Bondar, and R.M. Mason, Knowledgebased theory of the firm, challenges by social media, in System Science (HICSS), 2012 45th Hawaii International Conference on. 2012, IEEE. p. 3879-3887. Benitez, J., et al., IT-enabled knowledge ambidexterity and innovation performance in small U.S. firms: The moderator role of social media capability. Information \& Management, 2018. 55(1): p. 131-143.

[59] Luna, S. and M.J. Pennock, Social Media Applications and Emergency Management: A Literature Review and Research Agenda. International Journal of Disaster Risk Reduction, 2018.

[60] Yang, Z., et al. Virtual Collaboration with Mobile Social Media in Multiple-Organization Projects. in Proceedings of the 51st Hawaii International Conference on System Sciences. 2018.

[61] Baloh, P., The role of fit in knowledge management systems: Tentative propositions of the KMS design. Journal of Organizational and End User Computing, 2007. 19: p. 22.
El Said, G.R., Understanding Knowledge Management System antecedents of performance impact: Extending the Task-technology Fit Model with intention to share knowledge construct. Future Business Journal, 2015. 1: p. 75-87.

[63] Kuo, R.-Z. and G.-G. Lee, Knowledge management system adoption: exploring the effects of empowering leadership, task-technology fit and compatibility. Behaviour \& Information Technology, 2011. 30: p. 113-129.

[64] Lin, T.-C. and C.-C. Huang, Understanding knowledge management system usage antecedents: An integration of social cognitive theory and task technology fit. Information \& Management, 2008. 45: p. 410-417.

[65] Perkins, B., Social Media to the Rescue. Computerworld, 2010. 44: p. 16.

[66] Goodhue, D.L. and R.L. Thompson, Task-technology fit and individual performance. MIS quarterly, 1995: p. 213-236.

[67] Gudi, A., Effective knowledge integration in emergency response organizations. 2008.

[68] Tiwana, A. and E.R. Mclean, Expertise integration and creativity in information systems development. Journal of Management Information Systems, 2005. 22: p. 1343.

[69] Subramaniam, M. and N. Venkatraman, Determinants of transnational new product development capability: Testing the influence of transferring and deploying tacit overseas knowledge. Strategic Management Journal, 2001. 22: p. 359-378.

[70] Pearce, J.L. and H.B. Gregersen, Task interdependence and extrarole behavior: A test of the mediating effects of felt responsibility. Journal of Applied Psychology, 1991. 76: p. 838.

[71] King'ori, R., Explorong social media in organizational processes: a task-technology perspective. 2013.

[72] Öberseder, M., et al., Consumers' perceptions of corporate social responsibility: scale development and validation. Journal of Business Ethics, 2014. 124: p. 101-115.

[73] Netemeyer, R.G., W.O. Bearden, and S. Sharma, Scaling procedures: Issues and applications. 2003.

[74] Churchill Jr, G.A., A paradigm for developing better measures of marketing constructs. Journal of marketing research, 1979: p. 64-73.

[75] Subramaniam, M. and N. Venkatraman, Determinants of transnational new product development capability: testing the influence of transferring and deploying tacit overseas knowledge. Strategic Management Journal, 2001. 22(4): p. 359-378.

[76] Pearce, J.L. and H.B. Gregersen, Task interdependence and extrarole behavior: A test of the mediating effects of felt responsibility. Journal of Applied Psychology, 1991. 76(6): p. 838.

[77] King'ori, R., Explorong social media in organizational processes: a task-technology perspective, in Schools of Management and Governance. 2013, University of Twente: Netherland.

[78] Lin, T.-C. and C.-C. Huang, Understanding knowledge management system usage antecedents: An integration 
of social cognitive theory and task technology fit. Information \& Management, 2008. 45(6): p. 410-417.

[79] Tiwana, A., An empirical study of the effect of knowledge integration on software development performance. Information and Software Technology, 2004. 46(13): p. 899-906.

[80] Tiwana, A. and E.R. Mclean, Expertise integration and creativity in information systems development. Journal of Management Information Systems, 2005. 22(1): p. 13-43.

[81] Gudi, A., Effective knowledge integration in emergency response organizations, in College of Business Administration. 2008, Florida International University: United States.

[82] Hair Jr, J.F., et al., A primer on partial least squares structural equation modeling (PLS-SEM). 2016.

[83] Gismalla M.S, Abdullah M.F, Device to Device Communication for Internet of Things Ecosystem: An overview. International Journal of Integrated Engineering, Special Issue on Electrical Electronic Engineering and ReSENT, 2017. 9(4): p. 118-123. 